\title{
On the Application of Fraud Theory in the Field of Labor Contract
}

\author{
Wentao $\mathrm{Li}^{1,2}$ \\ ${ }^{1}$ School of Law, China University of Labor Relations, Peking, China \\ ${ }^{2}$ Civil and Commercial Law Research Center of Renmin University of China, Peking, China
}

\section{Email address:}

lilitaotaobyt@163.com

\section{To cite this article:}

Wentao Li. On the Application of Fraud Theory in the Field of Labor Contract. Journal of Human Resource Management. Vol. 6, No. 2, 2018, pp. 50-57. doi: 10.11648/j.jhrm.20180602.12

Received: June 1, 2018; Accepted: June 14, 2018; Published: July 10, 2018

\begin{abstract}
Judging whether a female employee's concealment of the fact of pregnancy constitutes fraud at the time of the conclusion of the labor contract requires starting from the constitutive elements of fraud and proceeding from the objectivie to subjective logical deduction-type argumentation analysis. Female employees generally have no obligations to actively inform the facts of pregnancy, and they passively conceal the silence of pregnancy facts which do not constitute fraud. Pregnancy generally does not belong to the important nature of female workers. The wrong statement of the female worker's pregnancy status does not constitute an important error. Female employees' false statements about the fact of pregnancy are generally not illegal and do not constitute fraud.
\end{abstract}

Keywords: Fraud, Error, Labor Contract

\section{Introduction: Seek Logic Deductions of Legal Argumentation}

It has been a controversial issue for female employees to conceal the fact of pregnancy constitutes fraud in civil law or not. It is also one of the hot and difficult issues in the labor contract law. This issue involves passive fraud, errors of nature, illegality of fraud, gender discrimination, equally treatment, the subjective intention of women workers, trust relationships, and many other civil and labor law issues, and even some issues of public law. Therefore, in judging whether it constitutes fraud or not, it is necessary to proceed from the basic theories of fraud in civil law. At the same time, combining the basic principles of labor law and the special rules of the labor contract law, the study should base on the specific facts of the case.

To some extent, any normative legal concept and legal system has its strict and detailed elements. To prove whether it is established or applicable, as the legal argument of the normative logic, the logical deduction-type argumentation is a kind of argumentation method that must be considered, that is, based on the constituent elements of the legal rules [1], an analytical approach to argumentation from objective to subjective layers. Therefore, under this mode of argumentation, whether female workers conceal the fact of pregnancy constitutes a fraud, we should proceed from the basic elements of fraud, and carry out logical and theoretical verification from the objective to the subjective.

Fraud refers to the fraudulent act (including the fabrication of false facts, false exaggeration of facts, misrepresentation, and keep silence if there is a duty of disclosure) on the part of the actor who deliberately commits an illegal act, which causes the another actors to make mistakes, maintain mistakes, or strengthen errors. The person makes a meaning because of this mistake. Fraud elements include the objective and subjective aspects. The objective level includes that the actor makes fraud, the other actor makes an error because of fraud, and the fraud is illegal. The subjective level includes that the actor has a subjective fraud intention.

Judgment of whether to constitute fraud should be demonstrated from objective to subjective, according to whether or not the perpetrator committed fraudulent acts $\longrightarrow$ whether the fraudulent act causes the ideographer to produce an error-whether or not the ideographer makes an erroneous representation $\longrightarrow$ Whether the fraudulent act is illegal or not $\rightarrow$ The subjective person has intentional intention, such a logic clue unfolds. [2] The argumentation process has a 
logical relationship and progressive relationship. All these requirements must be in conformity with one another before they constitute fraud.

According to the logical clues of the argument, whether the concealment of the fact of pregnancy from a female worker constitutes fraud or not, it is necessary to demonstrate whether the female employee commits fraud or not-whether the employer has made an error due to the fraudulent activity-whether the employer has made a mistake or not-whether the fraud of a female worker is illegal or not whether the fraud of a female employee has a subjective intention. That is to say, a logical deduction-type argument is being made to push through the hierarchy. If these conditions are all in agreement, women workers will conceal fraudulent facts of pregnancy. On the contrary, it does not constitute fraud This article attempts to use this as a logical clue, and combines depth with the theory of fraud and error and the theory and rules of labor law.

\section{Judgment of Fraud}

The actor's fraudulent act is the first step in deciding whether constitute fraud. Fraudulence, also known as fraudulent behavior, includes aggressive fraud and negative fraud.

Active fraud refers to false exaggeration of facts, false statements of facts, and false statements or explanations of actual facts. Negative fraud refers to violate the obligation to tell the truth, but keeping it silent. The concealment of the facts of pregnancy by female employees can be divided into positive concealment and negative concealment. Active concealment is active fraud. When employers explicitly question female employees, female employees make false statements and explanations. Negative concealment is passive fraud, which is the silent behavior of a female worker. When the employer asks whether she is pregnant, the female employee does not respond and keeps silent. It also includes the objective fact that the female employee did not take the initiative to inform and kept silent.

\subsection{Positive Fraud - False Statements}

To determine whether an active concealment by a female employee constitutes an active fraudulent activity, it is first necessary to analyze whether the employer's question is legal and whether the issue is related to the labor contract and whether it is an important issue that female employees must answer. If the employer's question about whether she is pregnant is illegal, the female employee is not obliged to answer the illegal question. Of course, it is also possible to give false answers, that is, the false statement is justified and legal. This issue is explained in detail in the following discussion on whether the concealment of a female worker is illegal.

Obviously, the employer's right to know is limited, and it can only question the situation concerning the labor relations to be established. For situations not related to the labor contract, based on Article 8(2) of the "Labor Contract Law" of
China, employers do not have the right to know. Regarding whether employers can ask whether a job seeker is pregnant, we should not only consider the interests of the "privacy protection" of the job seeker and the reasonable personnel arrangements of the employer, but also consider the principles of the welfare state and the legislation of the special group protection law. If the matters inquired by the employer may constitute discrimination prohibited by the law, the employer does not have a legitimate interest in obtaining the information [3] According to the German Federal Labor Court, questioning the pregnancy status usually means a gender discrimination that should be banned and it violates Article 611a of the Civil Code. If an employer asks an employee questions that are not allowed to be asked, it may result in an employer's liability for damages based on negligence in contracting and may even infringe upon the right of the female employee to personality. Therefore, employees can of course make untrue answers to questions that are not allowed. [4] The European Court of Justice even believes that the duration of the labor contract should not be distinguished and the employer must not ask whether the job seeker is pregnant. Most academic circles agree with the European Court of Justice. Fraud refers firstly to the question of employers being allowed to raise questions in a manner. [5]

\subsection{Negative Fraud - Silence}

Whether or not the female employee's silent behavior constitutes fraud is worth analyzing. Silence is also a legally significant act, sometimes called inaction. Silence can even be used as one of the means of expression, unless the law expressly states that it must express meaning in explicit or essential terms. [6]

It is generally believed that if the silence of an actor is used as a fraudulent activity, it must be premised on the actor's obligation to bear legal or agreed obligations. Larenz proposed that engaging in fraud in a silent manner (concealed) is only limited to the existence of explanatory obligations, depending on the behavior itself, the trading relationship (such as the sale of old cars, and the seller's reporting of traffic accidents that occurred before), Obligations and the trust relationship between the parties. [7] Judgment of obligations should specifically analyze the legal relationship that silence is aimed at. Only when the other party has the right to expect the other party to disclose the fact based on the contractual relationship, so the contracting party's conscious and silent behavior against other people's mistakes can constitute fraud, so the obligation of notification and silence should be regarded as an inseparable part. [8] It is only when the legal, contractual, transactional, or honesty doctrines inform the factual obligation that the party remain silent and hide the true objective facts that can constitute fraud. [9] The existence of a notification obligation but without notification is the basis for the fraudulent act of fraud.

The theory of civil law in Japan believes that in social life, to a certain extent, the perpetrator should be allowed to use other people's ignorance to remain silent, unless the law or the principles of faith require tell the truth. [10] Moreover, only 
when silence is in violation of the principle of good faith and is illegal, it constitutes fraud. [11] The first act of silence is illegal, that is, the actor has the obligation to provide information, and has the obligation or obligation to convey information to the other party. Second, the perpetrator has a fraudulent intention and deliberately includes an understanding of the mistake, that is, the relative recognizes that the other party does not know the fact; it also includes the knowledge of the illegality, that is, the fact that the party recognizes clearly that the fact should be communicated, but not tell. [12] Otherwise, silent acts do not constitute fraud. In Japanese law, unlawful silences must be combined with subjective fraud on the part of the actor to deliberately constitute fraud.

In German law, inaction (silence) can also constitute fraud if the law provides for an obligation to explain it, but the party without explaining it. However, if some factual issues have no obvious influence on the decision of the parties to the contract, and there is no significant meaning to the expression of the meaning, especially in some areas of personal privacy, the actor has no obligation to explain the issue. For example, the fact that the parties belong and the criminal records caused by the illegal acts are of no significance to the workers on the assembly line. However, due to the criminal record caused by traffic accidents, for truck drivers, the property crime record is of great significance to the accountant and the cashier. Therefore, the perpetrator is obliged to inform and should not maintain silence, otherwise it will constitute fraud. The obligation to explain can come from legal provisions, contractual agreements, or special trust relationships such as commercial relations or long-term close business relations. [13] This commercial connection can be derived from the implied terms and implied obligations of the contract.

In general, the obligation of a woman employee to inform her about her pregnancy is not an implied term in the contract. Because the pregnancy of a female employee is not important fact related to the labor contract, and the employer does not have the right to ask questions about the pregnancy of the female employee. A female employee may not inform this issue, and the parties cannot agree that they must be notified. Matters that are not permitted by law cannot be requested by the parties in the manner agreed in the contract. [14] Therefore, female employees do not have legal or agreed obligations to inform pregnant status, and their silence on the fact of pregnancy does not constitute fraud.

\subsection{Different Jurisprudence and Opinions}

There are also different jurisprudence and viewpoints on whether women workers are obliged to inform the facts of pregnancy. A jurisprudence of the German Federal Labor Court held that if a woman employee only has the obligation to work at night, she is even obliged to actively explain without permission if she is pregnant. [15] Some scholars even believe that questions about pregnancy and health are generally allowed. [16] Although the employed person does not need to actively inform him of the fact that he is already pregnant, he must be frankly stated when the employer asks about his or her health status. [17] The Federal Labor Court of Germany stated that if an employee's health status when entering into a labor contract is so poor that he may not be able to perform his work as required by the contract, the employee must truthfully explain the situation to the employer without asking. Of course, stricter standards should be applied only when there is a certain kind of special relationship of trust. [18] Undoubtedly, under the general framework of rules, there are still different cases and viewpoints. It may be that the special cases of certain individual cases and the measurement of case justice provide a basis for the justification of the obligation of women workers to take the initiative to inform, but the special thinking between the merits and the case still cannot illegally damage the legal and legitimate rights and interests of female employees.

\section{Whether the Employer Who Be Cheated Has Produced an Error}

If female employees are found to be fraudulent, then it is necessary to demonstrate whether the employer has made mistakes based on the fraudulent activity and made an intentional expression because of the error. There are two chains of causality among them. First, the fraud of female employees leads to an error of employer, and the fraudulent conduct of the female employee has a causal relationship with the employer's mistake. Second, the employer makes a meaning because of the mistake, and the error has a causal relationship with the meaning of the expression. Japanese law theory believes that the causality judgment must take into account the subjective causality, that is, it can be inferred that if there is no mistake, the ideographic person will not express such meaning. We must also consider the importance of the objective, that is, we can infer that if there is no mistake, the average person will not do that kind of meaning, that is, according to the normal trading concept, it is justified to not do that kind of meaning. [19] In short, if there is no such error, the employer will not make any intentional expression.

The essence of fraud is to affect the freedom of expression of the ideographs, resulting in the expression of the meaning of the ideographer. If the cheating does not cause the ideographer to express an ambiguity, there is no fraud in civil law. If the concealment of a female worker does not result in an employer's mistake and does not cause the employer's intentions to express defamation, his behavior does not constitute fraud. Therefore, whether the employer will make mistakes due to female employee fraud is the core issue of the argument.

In a sense, fraud and error are two aspects of a problem. As fraud is one of the elements of the mistake, it can always be regarded as a problem related to mistakes. [20] Fraud is precisely the premise that the fraudulent and erroneous people make mistakes through fraud, so the relationship between fraud and error becomes a problem. [21] The problem of fraud, in a sense, is a problem of wrong. Fraud refers to fraudsters who make mistakes, keep mistakes, or reinforce mistakes by 
fabricating false facts or distorting facts and concealing facts. [22] This should first begin with the explanation of the error theory.

\subsection{Error Theory}

The mistakes made by female employees in concealing their behaviors are obviously the category of motives and are the wrong understanding of the stage in which the employer's intentions are formed. The employer's inner and outer expressions are clearly the same, but the mistaken inner judgment was made based on the wrong understanding when forming the meaning expression. However, whether the employer's misunderstanding is an error in civil law or not is an important mistake that deserves attention. Can the employer erroneously claim cancellation of the labor contract based on this motive or the invalidity of the labor contract? It is worthy of in-depth analysis and demonstration.

Moreover the parties generally cannot revoke their meaning on the basis of their motives or claim that their meaning is invalid. Only if the motive is wrong and the transaction considers it important and constitutes an important mistake of nature, the party can claim revocation in accordance with the law. Article 119, paragraph 2 of the German Civil Code stipulates that errors in the nature of the qualifications or properties of persons considered to be important in the transaction may also be regarded as erroneous in the content of the meaning. It can be seen that only the wrong motives of the qualifications or properties of persons considered to be important in transactions are legally regarded as errors. That is, the important nature of mistakes in the wrong motivation (including the qualifications of people and the nature of things) can affect the effectiveness of legal actions. Therefore the employer's misconception of the status of the female worker's pregnancy is a major nature error. Whether or not the female worker's pregnancy status is an important nature or qualification of the female employee needs to begin with a specific analysis of the nature of the error.

\subsection{Mistakes in Nature}

The theory of the nature of error should be derived from a jurisprudence made by classical Roman jurists. The general definition of German judicial precedent is that the nature refers to all de facto and legal relationships that have an influence on the use or value of the subject matter of the transaction because of its characteristics and duration. French law stipulates that from the subjective point of view, the nature or qualifications of the parties to a contract are specifically considered by the parties to the contract at the time of conclusion of the contract, and the judge considers it to be an essential feature of the parties to conclude the contract. If it is not of this nature, the contract is cannot establish. [23] Errors of this nature directly affect the conclusion of the contract, directly affecting the expression of the intention, that is, without this misunderstanding, the contract will not be concluded. In particular, in regard to the qualifications of people, legal actions should only involve people's qualifications only when their qualifications are decisive for the legal relations formed through legal acts.

Whether the nature error is an important factor in determining the conclusion of the contract, whether the pregnancy status of the female employee is of an important nature or an important qualification of the party, whether the employer will produce an important nature error and enters into a labor contract. These issues need to be combined with the specifics of the labor contract law. The rules are analyzed.

\subsection{Whether the Employing Unit Has Caused an Error in the Nature (Wrong Qualifications of the Parties)}

The distinctive features of habitual significance (employee's character or qualifications) that are meaningful in German labor law include training, professional competence, health status, reliability, and so on. The nature of the worker should be of a long-term nature, and it denies that pregnancy is significant. And pregnancy is not the nature of a female worker. The important nature of the laborer is often judged according to the specific conditions of labor relations. [24] Larenz believes that women's pregnancy is not a nature because it is only a short-lived condition. Employers cannot revoke labor contracts because of the fact that women workers are pregnant. [25] Obviously, for a job seeker, pregnancy cannot be considered a feature because it is only a temporary state. What is important is only the characteristics directly related to the content of legal acts. Shi Shangkuan also proposed that women's pregnancy is a temporary, non-important qualification. Employed female workers cannot withdraw their labor contracts due to mistakes even if they are not informed of their pregnancy. [26]

Most people believe that the conception of female workers is not an important qualification or nature of the parties to a labor contract, and does not constitute an important factor affecting the conclusion of a labor contract. The mistaken understanding based on this does not belong to an important property that is subject to legal concerns. The employer cannot rely on this. Therefore, when female workers concealed the fact of pregnancy, the employer did not produce important errors of nature. The concealment of female employees does not constitute fraud.

\subsection{Exceptional Situations}

In the field of labor contracts, the conceiving status of female workers may also sometimes become an important property or qualification of the parties to a labor contract. The pregnancy status of female employees is an important property for female fashion models, female dancers, female athletes and other short-term labor relations. [27] Especially when pregnancy leads to the inability of the labor contract to be fulfilled, such as female fashion models, then pregnancy becomes an important conspicuous property of laborers. [28] Pregnancy of a female employee can be seen as an important property of the trader if she intends to engage in a short-term career that would make her unable to work most of the time. Social considerations and demanding thoughts have had an 
impact on the interpretation of this important nature. Therefore in special industries, special jobs, and short-term labor contracts, pregnancy status can become an important property or qualification of a female employee, and can be a key factor in influencing the conclusion of a labor contract. The employer's misunderstanding of the status of female employees can constitute a major problem. However, this requires specific analysis in individual cases and the need to consider social factors and the special protection of women workers' rights and interests.

\section{Whether the Fraudulent Act Is Illegal}

If the act of concealing the pregnancy status of a female worker constitutes a fraudulent act, which in turn causes the employer to produce an important property error, and the employer concludes a labor contract based on the error, it is necessary to further prove whether the concealment of the female employee has illegality. Because only fraudulent acts that constitute fraud constitute fraud, if the fraud is not illegal, it does not constitute fraud.

\subsection{Fraud Must Be Illegal and Constitute Fraud}

The theory of civil law in Japan holds that in social life, some deceptive behaviors should be allowed to go unpunished. Fraudulent acts are not illegal, and it is not fraud. [29] Not all fraud is identified as fraud, but fraudulent activity that meets the elements of illegality constitutes fraud. If the fraud is minor and does not obstruct the fairness of private interests in legal actions, the law may not intervene. [30] Fraud must be illegal in order to constitute fraud. Whether or not female workers conceal the fact of pregnancy is illegal and requires in-depth analysis based on the theory of discrimination in labor law. If the employer wants to cancel or terminate the labor contract on the grounds of pregnancy, which constitutes gender discrimination in the labor law and is an illegal act in the labor law, it is not illegal for the female employee to conceal the fact of pregnancy against the illegal sex discrimination. There is no doubt that the employer's unlawful discrimination against pregnant female workers cannot obtain legal support and does not damage the legal rights and interests of female employees because of the support for the illegal sex discrimination.

\subsection{Sex Discrimination Against Pregnant Female Employees Is Generally Illegal}

Features that are protected by anti-discrimination rules include: race, color, gender, language, religion, political orientation, nationality, geography, social class, property status, birthplace, and other characteristics. In this regard, there is a more comprehensive and updated provision in Article 21, paragraph 1, of the EU Charter. [31] In the Anglo-American law, the law on the protection of female workers during pregnancy has undergone major changes in recent years due to legislation implementing the Directive for Protecting Female Workers during Pregnancy. The court proposed that the unequal treatment of female employees during pregnancy due to reasons of pregnancy is direct gender discrimination. Discrimination against pregnant female workers is a form of direct discrimination and there is no defence. [32] It is now generally accepted that the issue of pregnancy raised before the commencement of employment without a fixed term constitutes an undisclosed gender discrimination (art. 1, Article 7, paragraph 1 of the General Equal Treatment Act). This rule also applies to time-limited labor relation (European Court of Justice Decision of October 4, 2001, Rs. C-109/00). [33] The Federal Labor Court of Germany considered that taking into account Article 611a and a directive of the European Economic Community, questions were asked on whether to become pregnant or not, and in the usual case gender discrimination, [34] and that sex discrimination is illegal.

In the Dekker case, the employer decided not to appoint an already pregnant applicant, even if she was the best candidate for the job. The court ruled that because the pregnancy was rejected for employment only for women, the refusal to appoint a person for a woman's pregnancy constitutes a direct discrimination based on sex. The court took a similar approach in the Webb case. Mrs. Webb was recruited by EMO Airlines to replace another employee who was on maternity leave, but soon after taking over the job, she was also pregnant. When she was fired, her claim was sexually discriminatory. The court ruled that the dismissal of a pregnant female worker who was employed for an indefinite period of time cannot justify the dismissal on the grounds that the other party could not perform the contract. The court also extended its approach in the Dekker case to the terms and conditions of employment. [35] Under normal circumstances, because the female worker is pregnant and cancels the contract, it constitutes direct gender discrimination and is illegal.

\subsection{Acts of Concealing the Facts of Pregnancy by Female Workers Are Generally Not Illegal}

Since the termination or withdrawal of a labor contract due to the fact of pregnancy generally constitutes discrimination on the basis of sex, so women workers are not required to answer questions about pregnancy,[36] and in the recruitment of female employees asked if they become pregnant as a principle not Allowed questions so that the employment contract concluded by the employer due to the wrong answer of the woman employee to the question cannot be revoked due to fraud. [37] Therefore female employees can make the wrong answer, that is, they have the right to lie. This right means that job seekers can basically hide their pregnancy and do not constitute an offence. That is, to make untrue answers to illegal questions does not constitute fraud. In order to obtain employment, female employees made untrue answers to questions that were not allowed (pregnancy status), and the deception was legal. Generally speaking, it is legal for women workers to hide the facts of pregnancy without illegality. However, there are also different cases and opinions. 


\subsection{Different Jurisprudence and Opinions}

There is a German case in which, when there is a legitimate and substantive reason for objectively questioning pregnancy status, such as when a job site poses a health risk to a female job applicant or her child, exceptions may be allowed (BAG NZA 1993, 257 U 933)[38]. If the law prohibits pregnant female employees from engaging in certain work, the employer will therefore clearly seek an employee who is a substitute for a pregnant female employee. In this case, Article $8(1)$ of the General Equal Treatment Act shall apply. The stipulation that "differential treatment" constitutes an important and decisive precondition for the completion of work tasks. [39]

\subsection{Different Rules - Tolerance of Sex Discrimination: Application of the Principle of Proportionality in Discrimination}

The prohibition of discrimination is not absolute, and discrimination is not absolutely illegal. In certain special circumstances, the court allows employers to adopt discriminatory measures to impose certain restrictions on workers, including measures that lead to gender discrimination. If the employer's gender discrimination measures adopted by female employees are lawful, it is illegal for female employees to use such sex discrimination measures to prove that concealing the fact of pregnancy has legitimacy and it is very difficult. If the special conditions and special requirements for a job are in line with the principle of proportionality, that is, it has a legitimate purpose, it is necessary for the job, and no other more equal alternative measures can be taken. The employer can make special requirements and conditions for the job. This includes special requirements for gender. Under special circumstances, it may also include requirements for the status of female employees' pregnancy. At this time, if sex discrimination measures for pregnant women employees are justified, the concealment of the facts of pregnancy will hardly gain legitimacy.

\section{The Subjective Intentional Considerations of Female Workers}

The subjective aspects of female workers are the final considerations. If all of the aforementioned constituent elements are in compliance, it is also necessary to consider whether the female employee subjectively has a fraudulent intention. If the female employee subjectively does not have the intention, his concealment does not constitute fraud.

\subsection{Fraudulent Intentional Constituent Requirements}

Fraud is the intentional mentality of harming others when the act is carried out. [40] The subjective mentality of the actor is intentional. Fraud deliberately intentionally causes or maintains some kind of error in order to achieve the purpose of influencing the decision-making of the person who is being defrauded, only fraudulent intentional to make the ideographer to make mistakes, it constitutes fraud, the fraud requires the perpetrator to be subjectively intentional, malicious or intentional.

Japanese law believes that the intention of fraud includes two intentions, one is the intention to cause some kind of error. The second is to induce ideographers to intentionally express the intention through fraud. If the party has already decided to issue a meaning statement, then there is no malicious. That is, the intention of the actor directly causes the party to make an intentional expression based on the error caused by the fraud. Shi Shangkuan believes that the actor's intention includes three intentions, the first is the intention to fall into error, the second is the intention based on the meaning of mistakes, and finally the intention of his own benefit and the other party's damage. [41] The German legal theory holds that the fraudulent constitution does not require that the fraudulent person has the intention to damage the property rights and interests of the ideographer', but only requires that it influence the ideographer's intention to express the decision. The German Federal Supreme Court held that if the perpetrator intends to defraud the perpetrator of the best interests, it does not constitute fraud. [42] Of course, the opinions of the jurisprudence may also be abused, and even become an excuse to avoid fraudulence.

\subsection{The Fact That the Female Worker Conceals Pregnancy Without Subjective Malice Does Not Constitute Fraud}

From the analysis of the above fraudulent and malicious constituent requirements, if female workers do not have subjective intentions to hide the facts of pregnancy, there is no intention that causes employers to make mistakes, or there is no intention that employers make intentional expressions based on the errors. Or, if there is no intention to harm the interests of the employer and benefit oneself (but for the best interests of the employer), it does not constitute fraud. If a female employee mistakenly believes that the employer has already known the fact that he is pregnant and fails to inform the employer, his concealment does not exist subjectively and fraudulently, does not constitute fraud.

\section{Conclusion}

In accordance with the above progressive argumentation method, if the female employees' concealment of the facts of pregnancy one by one meets each of the above constituent elements, they can be deemed to constitute fraud by law. Otherwise, they do not constitute fraud. At this time, the conclusion does not seem to be so important, but the ideas and methods of promoting the arguments at various levels may be more valuable. The specific judgments of special legal relationships and case facts may be more realistic, and various different cases and opinions may be more intelligent knowledgeable challenges.

To some extent, the fundamental theory and basic system of civil law can only find the basis for its legitimacy and rationality through the application of specific laws. The life of the law stems from a living social life, and civil law is no 
exception. The practice and theories of labor law provide rich life materials for the development of civil law, and it also provides a constant source of momentum for the evolution of civil law theory - which also constitutes one of the traces of the historical development of civil law.

\section{Acknowledgements}

The paper has been supported by the fund of the research program, on the establishment of legal act, of China University of Labor Relations.

Grateful acknowledgement is made to editor who gave me considerable help by means of suggestion, comments and criticism. And I deeply appreciate the contribution to this thesis made in various ways by my friends and colleagues. Last but not least, I owe much to my university, China University of labor relations, for her valuable support and she give me a good research environment.

\section{References}

[1] Da Yiren, An Introduction to Criminal Law, translated by Feng Jun, Renmin University of China Press, 2003, p. 111.

[2] Blox, The General Theory of German Civil Law, translated by Zhang Yan, Chinese people University Press, 2012, pp. 272-281.

[3] Wolfgang Doyle Pler, The German Labor Law, translated by Wang Qian, Shanghai People's Publishing 2016, pp. 140-156.

[4] Dutz, Labor Law, translated by Zhang Guowen, Law Press 2005, pp. 39-40.

[5] Raymond Walterman, German Labor Law, translated by Shen Jianfeng, Law Press, 2014, p. 136-145.

[6] Karl Larenz, The General Theory of German Civil Law, translated by Wang Xiaoye etc., Law Press, 2007, pp. 485-491.

[7] Karl Larenz, The General Theory of German Civil Law, translated by Wang Xiaoxuan etc., Law Press, 2007, pp. 542-543.

[8] Werner Flume, The Legal Act, translated by Chi Ying, Law Press, 2013, pp. 644-647.

[9] Shi Shangkuan, The General Civil Law, China University of Political Science and Law Press, 2000, pp. 407-408.

[10] Woqi Rong, The General Principles of the New Civil Law, translated by Qu Tao, Chinese Legal Publishing House, 2009, pp. 288-290.

[11] Jinjiang Xingzhi, The Civil Law Lecture I General Principles of Civil Law, translated by Qu Tao, Peking University Press, 2015, p. 205.

[12] Shanben Jingsan, Civil Law Lecture I General Principles, translated by Xie Gen, Peking University Press, 2012, pp. 181-187.

[13] Hans Thoma, Bürgerlichen Recht Allgemeiner Teil, Verlag W. Kohlhammer, 1975, pp. 188-189.
[14] Wang Zejian, General Principles of Civil Law, China University of Political Science and Law Press, 2001, p. 377.

[15] Dieter Medicus, Allgemeiner Teil des BGB, CFMüller Verlag Heidelberg, 2006, pp. 311-312.

[16] Hans Thoma, Bürgerlichen Recht Allgemeiner Teil, Verlag W. Kohlhammer, 2005, pp. 188-189.

[17] Huang Yueqin, New Theory of Labor Law, China University of Political Science and Law Press, 2003, p. 125.

[18] Dieter Medicus, General Theory of German Civil Law, Translated by Shao Jiandong, Legal Press 2006, p. 602.

[19] Shanben Jingsan, The General Principles of Civil Law Lecture I, translated by Xie Gen, Peking University Press, 2012, p. 166.

[20] Shanben Jingsan, The General Principles of Civil Law Lecture I, translated by Xie Gen, Peking University Press, 2012, p. 186.

[21] Jingjiang Xingzhi, Civil Law Lecture I General Principles of Civil Law, translated by $\mathrm{Qu}$ Tao, Peking University Press, 2015, p. 205.

[22] Hanns Prütting, Gerhard Wegen, Gerd Weinreich, $B G B$ Kommentar, Luchterhand, 2010, pp. 113 -115.

[23] Werner Flume, The Legal Act, translated by Chi Ying, Legal Press, 2013, pp. 516-529.

[24] Dutz, Labor Law, translated by Zhang Guowen, Law Press, 2005, pp. 46-48.

[25] Karl Larenz, Allgemeiner Teil des Bürgerlichen Rechts, Verlag C. H. Beck Müchen, 2004, p. 661.

[26] Shi Shangkuan, "General Theory of Civil Law”, China University of Political Science and Law Press, 2000, pp. 407-408.

[27] Hans Thoma, Bürgerlichen Recht Allgemeiner Teil, Verlag W. Kohlhammer, 2005, pp. 186-187.

[28] Dutz, Labor Law, translated by Zhang Guowen, Law Publishing House, 2005, pp. 46-48.

[29] Woqi, Rong, The General Principles of the New Civil Law, translated by Qu Tao, China Legal Publishing House, 2009, pp. 288-290.

[30] Hong Xunxin, General Principles of China Civil Law, 1993, pp. 404-406.

[31] A. C. L. Davies, Perspectives on Labour Law, Cambridge University Press, 2004, pp. 122-135.

[32] Deborah J. Lockton, Employment Law, Palgrave Macmillan, 2003, pp. 129-130.

[33] Raymond Walterman, German Labor Law, translated by Shen Jianfeng, Legal Press, 2014, pp. 136-145.

[34] Diete Medicus, Allgemeiner Teil des BGB, CFMüller Verlag Heidelberg, 2006, pp. 311-312.

[35] Katherine Barnard, EU Labor Law, translated by Fu Yan, Chinese Legal Publishing House, 2005, pp. 286-296.

[36] Hanns Prütting, Gerhard Wegen, Gerd Weinreich, $B G B$ Kommentar, Luchterhand, 2010, pp. 113-115. 
[37] Karl Larenz, Allgemeiner Teil des Bürgerlichen Rechts, Verlag CH Beck Müchen, 2004, p. 684.

[38] Dutz, Labor Law, translated by Zhang Guowen, Law Press 2005, pp. 39-40.

[39] Wolfgang Doyle Puller, The German Labor Law, translated by Wang Qian, Shanghai People's Publishing House, 2016, pp. 140-156.
[40] Pietro Pendev, Roman Law Textbook, translated by Huang Feng, China University of Political Science and Law Press, 1998, pp. 70-74.

[41] Shi Shangkuan, General Civil Law, China University of Political Science and Law Press, 2000, pp. 424-426.

[42] Werner Flume, The Legal Act, translated by Chi Yingying, Legal Press, 2013, pp. 644-647. 